$16^{\text {th }}$ International Conference on

AEROSPACE SCIENCES \& AVIATION TECHNOLOGY,

ASAT - 16 - May 26 - 28, 2015, E-Mail: asat@ mtc.edu.eg

Military Technical College, Kobry Elkobbah, Cairo, Egypt

Tel : +(202) 24025292 - 24036138, Fax: +(202) 22621908

\title{
Development of A PID Controller for Active Car Suspension System Using Adaptive Weighted PSO Algorithm
}

\author{
Magdy A.S. Aboelela*, Rania H. M. Hennas ${ }^{\dagger}$, Hassen T. Dorrah ${ }^{\star}$
}

\begin{abstract}
This paper focuses on the application of PI/PID controller tuned by Adaptive Weighted Particle Swarm Optimization (AWPSO) algorithm to car suspension system. The optimization step has been achieved based on three error criterion. These are: The Integral of Square Error (ISE), the Integral of Absolute Error (IAE) and the Integral of Time Absolute Error (ITAE). Also the obtained results have been compared with the outcomes of Ziegler- Nichols tuning methodology of the PID controller. Better performance of the PID tuned by the AWPSO proposed algorithm is noticeable. Finally, resources related to the AWPSO setting and initialization are listed. The system simulation and tuning of the PID controller have been achieved using MATLAB/Simulink tool.
\end{abstract}

Keywords: AWPSO, Active Suspension System, PID controllers

\section{Introduction}

At present, vehicle suspension has obtained high performance damping effect by using optimal control method. Industrial countries have begun to study an active, semi-active suspension system based on vibration control in the 1970s. In the 1960s, foreign scholars have proposed the concept of active suspension. Industry developed in the 70's has been of active[1-2], semi-active[3-4] suspension system based on the active vibration control.

Car suspension system is an integral part of the vehicle $[5,6]$ that affects the ride comfort of passengers by minimizing the vibration against different load conditions. In other word, the suspension system function is to isolate the vehicle body from road disturbances and inertial disturbances like braking. Many types of suspension system have been implemented over the years like passive suspension system and active suspension system. Passive suspension system uses mechanical spring for storing energy and damper for absorbing that energy [7, 8] and do not require extra power. While, active suspension system can produce an improved ride quality with additional power provided. In active suspension system, some kinds of suspension force generation are utilized [9] which act parallel to the suspension system located between the tire and the vehicle body. The actuator uses the suspension space while pushing up or pulling down in order to suppress its vibrations due to the road irregularities. The two main variables used for design and evaluation of the suspension system are vehicle body acceleration which determines ride comfort and suspension deflection which indicates the limit of the vehicle body motion [10].

Many researchers, in the last decade, have different techniques such as applied optimal control [11], $\mathrm{H}_{\infty}$ based controllers [12-14], nonlinear adaptive control[15], adaptive sliding control with self tuning fuzzy compensation [16], fuzzy logic [17-19], artificial neural

\footnotetext{
*Faculty of Engineering, Cairo University, Giza, Egypt. aboelelamagdy@yahoo.com

† MSc. Student, Faculty of Engg., Cairo University, Giza, Egypt. rony_rany@yahoo.com

${ }^{\star}$ Faculty of Engineering, Cairo University, Giza, Egypt; dorrahht@aol.com
} 
network[20-22], back stepping control [23], intelligent controllers [24], model reference adaptive controllers [25], and proportional-integral-derviative (PID) controllers [26] to the vibration control problem of vehicle suspension system.

The development of approaches used to tune the response of controllers range from trial and error, Root locus and linear optimal control techniques, and then computational intelligence approaches. Advanced computational intelligence techniques have been evolved by observing complex behaviors of human and other animals, event happening in nature and arrive at a mathematical model representing criteria under study.

Particle Swarm Optimization (PSO) algorithm is founded by Kennedy and Eberhart in 1995 [27-29]. The algorithm has been further improved into Adaptive Weighted PSO (AWPSO) later on for enhancing the performance of PSO [30-31]. The application of implementing the AWPSO to tune a class of PID controllers has been tried on many application in literature [32]. In this paper, AWPSO approach is utilized for tuning a PI/PID controller. AWPSO approach is evaluated through active suspension system for proving the suitability and the rigidity of that technique.

This paper is organized as follows. Section 2 introduces the PID controller. Section 3 shows the Adaptive Weighted Particle Swarm (AWPSO) technique. In section 4, the implantation of the AWPSO to tune the PID controller is presented. Section 5 gives the application procedure of the AWPSO techniques. In section 6, results and discussion of the salient points of the article is shown. Main references are given in section 7.

\section{PID Controller}

PID controller is considered as a basic component of industrial control system because of its capability of improving the dynamic behavior of the system and reducing the steady state error. PID controller includes three parameters $k_{p}, k_{i}$ and $k_{d}$ where $k_{p}$ depends on the present error, $k_{i}$ depends on accumulation of past errors and $k_{d}$ is a prediction of future errors based on current rate of change. The transfer function for the PID controller is given as

$$
C(s)=k_{p}+\frac{k_{i}}{s}+k_{d} \mathrm{~s}
$$

\section{Adaptive Weighted Particle Swarm Optimization (AWPSO)}

Particle swarm optimization is one of the swarm intelligence forms in which the behavior of biological social system like a flock of bird or a school of fish [28] is simulated. This algorithm is introduced by Eberhart and Kennedy in 1995 [27-28]. Each particle keeps track of its coordinates in the problem space, which is associated with the best position (solution) it has achieved. This position is called $P_{\text {best }}$. Another best value that is tracked by the global version of the particle swarm optimizer is the overall best value and its location is called $g_{\text {best }}$ obtained by any particle in the swarm. The performance of each particle is evaluated using fitness (cost) function [29]. The PSO is represented mathematically in a form of Particle Velocity $V_{i j}(t)$ and Particle position $X_{i j}(t)$ as follows

$$
\begin{aligned}
& V_{i j}(t)=\mathrm{W} \cdot V_{i j}(\mathrm{t}-1)+C_{1} \cdot \operatorname{rand}(0,1) \cdot\left(P_{\text {best }}-X_{i j}(\mathrm{t}-1)\right)+C_{2} \cdot \operatorname{rand}(0,1) \cdot\left(g_{\text {best }}-\right. \\
& \left.\left.X_{i j}(\mathrm{t}-1)\right) 2\right) \\
& \left.\quad X_{i j}(t)=X_{i j}(t-1)+V_{i j}(t)\right)
\end{aligned}
$$




$$
\begin{aligned}
& i=1,2,3 \ldots, N \\
& j=1,2,3 \ldots, d
\end{aligned}
$$

Where

Where

$V_{i j}(t) \quad$ Velocity of the particle $i$ at iteration $\mathrm{t}$;

$X_{i j}(t) \quad$ Current position of particle $i$ at iteration $\mathrm{t}$;

$W$

Inertia weight;

$C_{1}, C_{2} \quad$ Cognitive and social acceleration coefficient;

rand $(0,1)$ random number between 0 and 1 ;

$P_{\text {best }}$. Particle $i$ best position;

$g_{\text {best }} \quad$ Global best position;

$N \quad$ Number of particles;

d Dimension;

$t \quad$ time;

The AWPSO algorithm is developed later by Mahfouf [6] for improving the performance of the PSO algorithm. The adaptive Weighted PSO is achieved by two terms: Inertia weight (W) and Acceleration factor (A).The inertia weight function is to balance global exploration and local exploration [7]. It controls previous velocities effect on the new velocity. Larger the inertia weight, larger exploration of the search space while smaller the inertia weights, the search will be limited and focused on a small region in the search space [8,9]. The inertia weight formula is as follows which makes $\mathrm{W}$ value changes randomly from $W_{o}$ to 1 :

$$
W=W_{o}+\operatorname{rand}(0,1)\left(1-W_{o}\right)
$$

Where $W_{o}$ is an initial positive constant in the interval $[0,1]$

The Acceleration factor formula is

$$
A=A_{o}+\frac{i}{n}
$$

Where $A_{o}$ is an initial positive constant in the interval $[0.5,1]$

The particle Velocity $V_{i j}(t)$ is rewritten incorporating Acceleration factor as follows:

$V_{i j}(t)=\mathrm{W} \cdot V_{i j}(\mathrm{t}-1)+\mathrm{A} \cdot C_{1} \cdot \operatorname{rand}(0,1) \cdot\left(P_{b e s t}-X_{i j}(\mathrm{t}-1)\right)+A \cdot C_{2} \cdot \operatorname{rand}(0,1) \cdot\left(g_{\text {best }}-\right.$ $\left.X_{i j}(\mathrm{t}-1)\right)$

\section{PI/PID controller Tuning procedure using AWPSO}

The search procedures of the AWPSO for finding the optimal values of the PID controller are as follows:

Step 1: Specify upper and lower bound of the PID controller parameter. The upper and lower bound values depend on the controlled system characteristics.

Step 2: Initialize randomly the particles position and velocity.

Step 3: Calculate the values of the cost function in the time domain.

Step 4: Compare each particle evaluation values with its best position $P_{\text {best }}$. The best evaluation value among the $P_{\text {best }}$ value is denoted as $g_{\text {best }}$. 
Step 5: Update the velocity of each particle in the swarm according to the following formula

$V_{i j}(t)=\mathrm{W} \cdot V_{i j}(\mathrm{t}-1)+\mathrm{A} \cdot C_{1} \cdot \operatorname{rand}(0,1) \cdot\left(P_{b e s t}-X_{i j}(\mathrm{t}-1)\right)+A \cdot C_{2} \cdot \operatorname{rand}(0,1) \cdot\left(g_{\text {best }}-X_{i j}(\mathrm{t}-1)\right)$

Step 6: Update the position of each particle in the swarm according to the following formula

$\left.X_{i j}(t)=X_{i j}(t-1)+V_{i j}(t)\right)$

Step 7: Update particle best position and global best position.

Step 8: Repeat the cycle again until maximum number of iteration is reached.

Step 9: When the number of iteration reaches its maximum value, then the latest global best position value is considered as the optimal value for the controller parameter.

\section{Application}

\subsection{Car Active Suspension System}

Car suspension system is an integral part of the vehicle that affects the ride comfort of passengers by minimizing the vibration against different load conditions [5]. In other word, the suspension system function is to isolate the vehicle body from road disturbances and inertial disturbances like braking. Many types of suspension system have been implemented over the years like passive suspension system and active suspension system. Passive suspension system uses mechanical spring for storing energy and damper for absorbing that energy [6-7] and do not require extra power. While, active suspension system can produce an improved ride quality with additional power provided. In active suspension system, some kinds of suspension force generation are utilized [8] which act parallel to the suspension system located between the tire and the vehicle body. The actuator uses the suspension space while pushing up or pulling down in order to suppress its vibrations due to the road irregularities. The two main variables used for design and evaluation of the suspension system are vehicle body acceleration which determines ride comfort and suspension deflection which indicates the limit of the vehicle body motion [9]. The schematic diagram for car suspension system is shown in Figure 1.

The mathematical representation of the suspension system is illustrated as follows

$m_{1}\left[\frac{d^{2} X}{d t^{2}}\right]=-B\left(\frac{d X}{d t}-\frac{d Y}{d t}\right)-k_{1}(X-Y)+U$

$m_{2}\left[\frac{d^{2} Y}{d t^{2}}\right]=B\left(\frac{d X}{d t}-\frac{d Y}{d t}\right)+k_{1}(X-Y)+k_{2}(z-Y)-U$

The controlled variable is the suspension system deflection $(\mathrm{X}-\mathrm{Y})$ as shown the block diagram shown in Figure 2. 


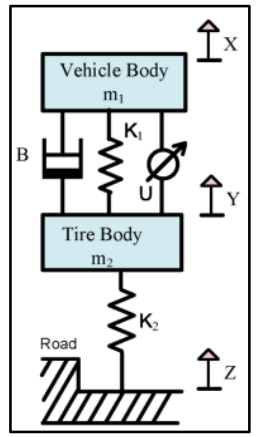

Figure 1: Car Suspension System

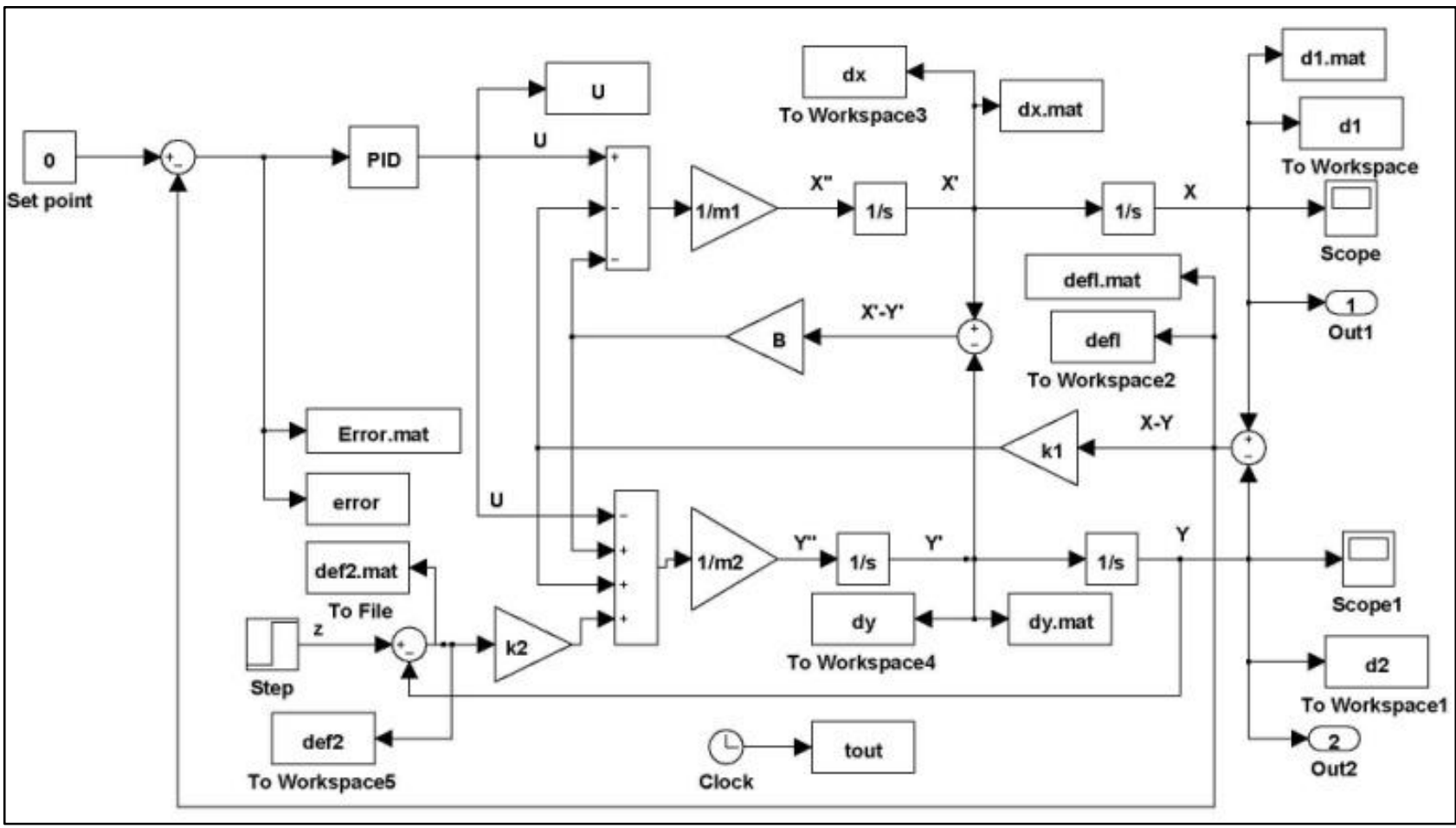

Figure 2: Car Active Suspension System Simulation diagram made using MATLAB/Simulink Tool

A step road disturbance acted on the system in block diagram is $0.08 \mathrm{~m}$. The error signal acts as an input to the controller.

\subsection{Objective function}

The control objective in this system is to minimize the deflection between the Vehicle body displacement $\mathrm{X}$ and Tire Body displacement $\mathrm{Y}$.

Error signal from the system, 'error' as delineated in Figure 2, will be taken as an input to the controller. The performance indices are utilized to implement the objective function ' $f$ ' as shown' below. The error term ' $e(t)$ ' given in equations 13 to 15 below will be considered equal to the system error signal 'error' of Figure 2.

For IAE

For ISE

$$
I A E=\int_{0}^{\infty}|e(t)| d t
$$

$$
I S E=\int_{0}^{\infty}\left|e^{2}(t)\right| d t
$$


For ITAE ITAE $=\int_{0}^{\infty} t|e(t)| d t$

The objective function is as follows:

$$
f=0.5\left(e^{2}+X^{2}+Y^{2}+\left(\frac{d X}{d t}\right)^{2}+o s w^{2}\right)
$$

Where osw is overshoot value.

\subsection{Parameters Values}

The description and the values of parameters indicated in the block diagram in Figure 2 are listed in Table 1.

Table 1: Parameters Values

\begin{tabular}{|c|l|c|}
\hline $\begin{array}{c}\text { Parameter } \\
\text { name }\end{array}$ & \multicolumn{1}{|c|}{ Description } & Value \\
\hline $\boldsymbol{m}_{\boldsymbol{1}}$ & Quarter car sprung mass (KG) & 250 \\
\hline $\boldsymbol{m}_{\boldsymbol{2}}$ & Tire mass (KG) & 50 \\
\hline $\boldsymbol{B}$ & Damping coefficient of suspension system damper (Ns/m) & 1000 \\
\hline $\boldsymbol{k}_{\boldsymbol{1}}$ & Suspension system spring stiffness (N/m) & 18600 \\
\hline $\boldsymbol{k}_{\boldsymbol{2}}$ & Tire spring stiffness (N/m) & 196000 \\
\hline $\boldsymbol{X}$ & Vehicle body displacement (m) & Varying \\
\hline $\boldsymbol{Y}$ & Tire body displacement (m) & Varying \\
\hline$\frac{\boldsymbol{d} X}{\boldsymbol{d} \boldsymbol{t}}$ & Vehicle body speed (m/sec) & Varying \\
\hline$\frac{\boldsymbol{d} \boldsymbol{Y}}{\boldsymbol{d} \boldsymbol{t}}$ & Tire body speed (m/sec) & Varying \\
\hline$\frac{\boldsymbol{d}^{\mathbf{2}} \boldsymbol{d}}{\boldsymbol{d} \boldsymbol{t}^{\mathbf{2}}}$ & Vehicle body acceleration (m/sec $\left.{ }^{2}\right)$ & Varying \\
\hline
\end{tabular}

\subsection{Simulation}

The car suspension system presented is tested once with PID controller tuned with AWPSO and once with PID controller tuned with Zeigler and Nichols tuning methods [32].

The graphs for Deflection (X-Y) and Vehicle height $\mathrm{X}$ are displayed for each of IAE, ISE and ITAE performance index. In addition the graph for Vehicle body Height $\mathrm{X}$ is shown with PID controller tuned with Zeigler and Nichols. 


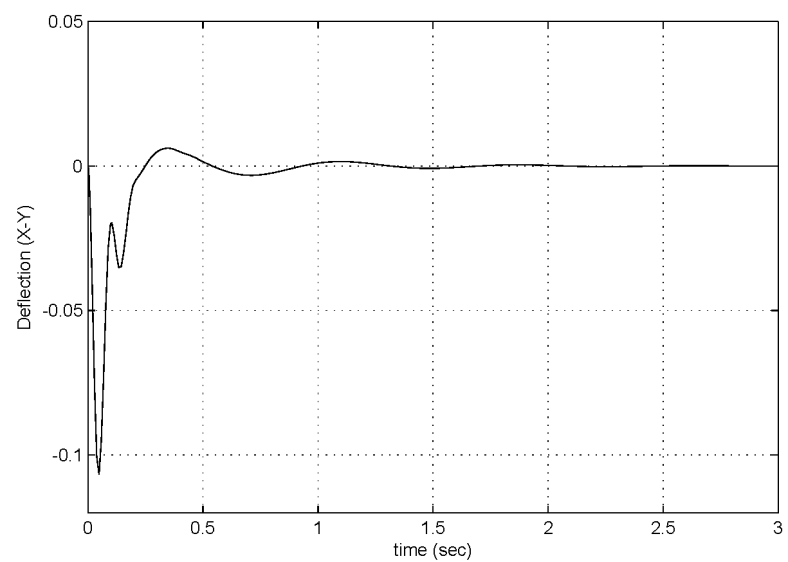

Figure 3: Deflection (X-Y) With PID-AWPSO Based on IAE

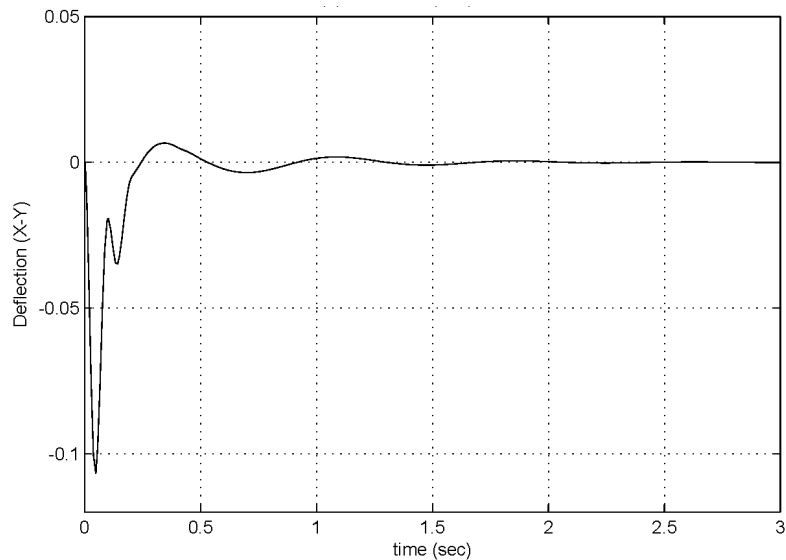

Figure 4: Deflection (X-Y) With PID-AWPSO Based on ISE

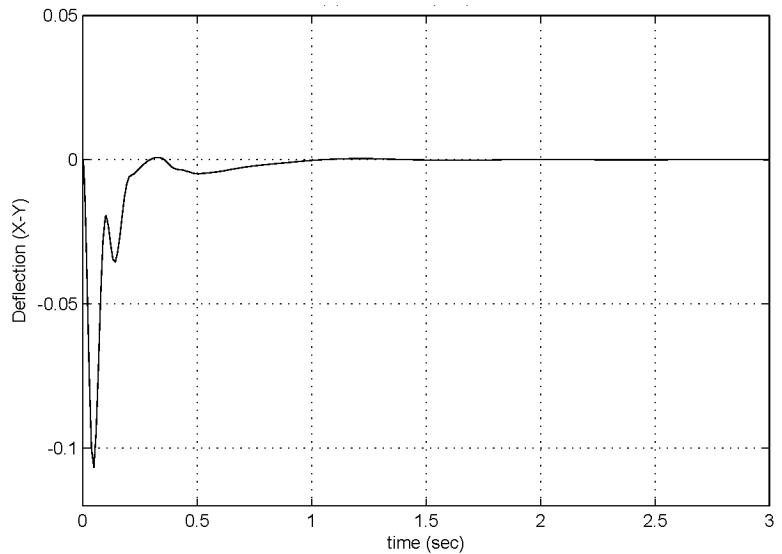

Figure 5: Deflection (X-Y) With PID-AWPSO Based on ITAE 


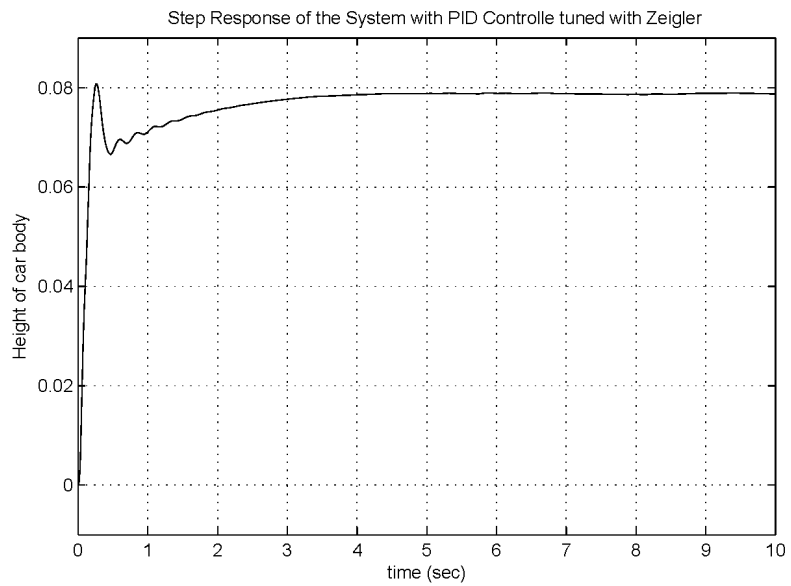

Figure 6: Car body height (X) With PID-Ziegler \& Nichols

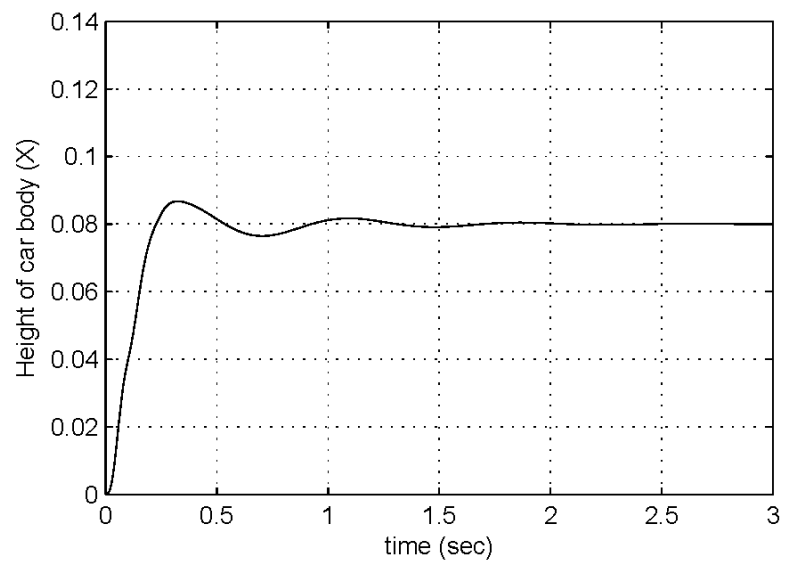

Figure 7: Car body height (X) With PID-AWPSO Based on IAE

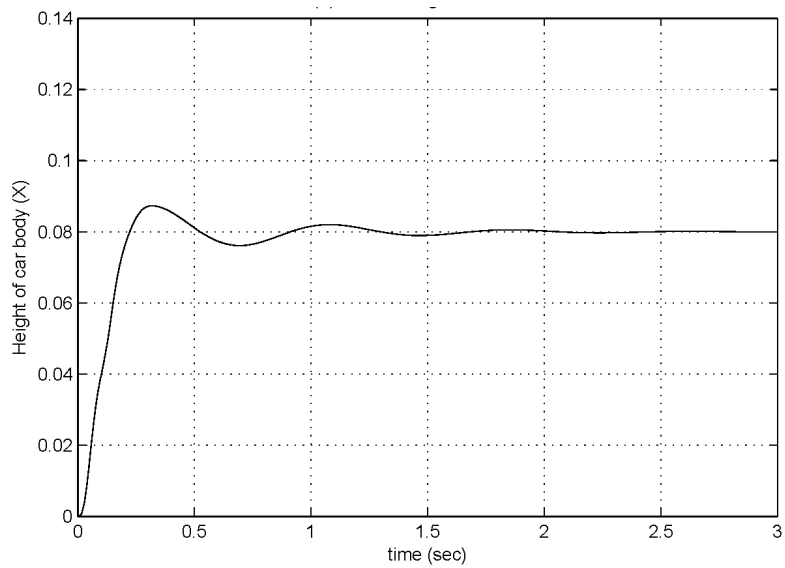

Figure 8: Car body height (X) With PID-AWPSO Based on ISE 


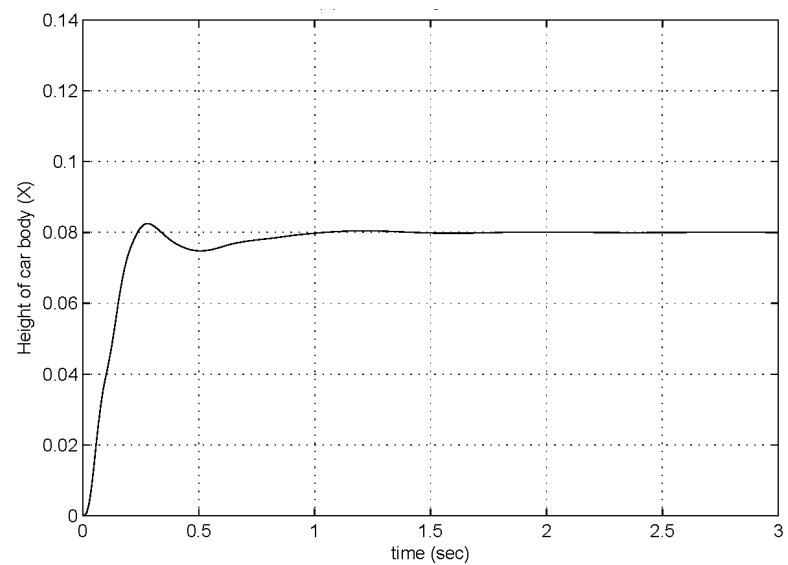

Figure 9: Car body height (X) With PID-AWPSO Based on ITAE

The settling time, overshoot, overshoot values along with PID controller gains values are mentioned in Table 3.

Table 3: Simulation results with PID-AWPSO

\begin{tabular}{|c|c|c|c|}
\hline Description & $\boldsymbol{I A E}$ & $\boldsymbol{I S E}$ & ITAE \\
\hline settling time & 1.1330 & 1.1626 & 0.8195 \\
\hline overshoot & 0.0867 & 0.0873 & 0.0815 \\
\hline $\boldsymbol{K}_{\boldsymbol{p}}$ & $2.5987 \mathrm{e}^{+003}$ & $8.4190 \mathrm{e}^{+003}$ & 977.3095 \\
\hline $\boldsymbol{K}_{\boldsymbol{i}}$ & $7.6149 \mathrm{e}^{+003}$ & $9.7759 \mathrm{e}^{+003}$ & $5.1691 \mathrm{e}^{+003}$ \\
\hline $\boldsymbol{K}_{\boldsymbol{d}}$ & $3.5904 \mathrm{e}^{+003}$ & $3.7022 \mathrm{e}^{+003}$ & $9.0393 \mathrm{e}^{+003}$ \\
\hline
\end{tabular}

\subsection{AWPSO Parameters}

The chosen AWPSO parameters values are listed in Table 4 below.

Table 4: AWPSO Parameters

\begin{tabular}{|c|l|}
\hline parameters & Value \\
\hline $\boldsymbol{N}$ & 50 particles \\
\hline $\boldsymbol{n}$ & 500 iterations \\
\hline $\boldsymbol{d}$ & 3 variables \\
\hline $\boldsymbol{C}_{\boldsymbol{I}}$ & 2 \\
\hline $\boldsymbol{C}_{\boldsymbol{2}}$ & 2 \\
\hline $\boldsymbol{W}_{\boldsymbol{o}}$ & 0.15 \\
\hline $\boldsymbol{A}_{\boldsymbol{o}}$ & 0.5 \\
\hline $\boldsymbol{X}_{\text {Orange }}$ & {$[010000]$} \\
\hline
\end{tabular}

\subsection{Summary of Simulation}

The simulation results using AWPSO algorithm is better than the simulation results in [33] which uses PID controllers tuned with Zeigler and Nichols tuning rules. In the case of AWPSO, the settling time for IAE, ISE and ITAE performance indices is less than 1.5 seconds. However with conventional PID with Zeigler and Nichols it is 4 seconds.

In addition that in the case of AWPSO, the minimum settling time and overshoot was achieved with ITAE performance index. The model was tested with PI controller, but it didn't yield to a good results. 


\section{Discussion and Conclusion}

This paper presents a design for PI/PID controller tuned buAdaptive Weighted Particle Swarm Optimization (AWPSO) algorithm. This control approach proved its efficient performance through application on car active suspension system.

It is clear that the proposed control approach is capable of reducing settling time with a measurable value. Furthermore, the overshoots, undershoots and ripples are minimized. The systems response evidences that the proposed control approach is reliable and robust without reliance on system models. The difficulties faced in utilizing AWPSO was choosing the appropriate AWPSO parameters in the presence of non-linearity in the systems model. In addition to specifying the suitable objective function along with the controller gains.

\section{List of Symbols}

\begin{tabular}{|c|c|}
\hline$m_{1}$ & Quarter car sprung mass (KG) \\
\hline$m_{2}$ & Tire mass $(\mathrm{KG})$ \\
\hline $\boldsymbol{B}$ & Damping coefficient of suspension system damper (Ns/m) \\
\hline$k_{1}$ & Suspension system spring stiffness $(\mathrm{N} / \mathrm{m})$ \\
\hline$k_{2}$ & Tire spring stiffness $(\mathrm{N} / \mathrm{m})$ \\
\hline$X$ & Vehicle body displacement (m) \\
\hline $\boldsymbol{Y}$ & Tire body displacement (m) \\
\hline$\frac{d X}{d t}$ & Vehicle body speed (m/sec) \\
\hline$\frac{d Y}{d t}$ & Tire body speed $(\mathrm{m} / \mathrm{sec})$ \\
\hline$\frac{d^{2} X}{d t^{2}}$ & Vehicle body acceleration $\left(\mathrm{m} / \mathrm{sec}^{2}\right)$ \\
\hline$N$ & Number of particles \\
\hline$n$ & Number of iterations \\
\hline$d$ & Dimension \\
\hline$C_{1}$ & Cognitive acceleration coefficient \\
\hline$C_{2}$ & Social acceleration coefficient \\
\hline$W_{o}$ & initial positive constant in the interval $[0,1]$ \\
\hline$A_{o}$ & initial positive constant in the interval $[0.5,1]$ \\
\hline$X_{\text {Orange }}$ & Range for the variables $(\mathrm{Kp}, \mathrm{Ki}$ and $\mathrm{Kd})$ \\
\hline
\end{tabular}




\section{References}

[1]. G. Priyandoko, M. Mailah, H. Jamaluddin, "Vehicle active suspension system using skyhook adaptive neuro active force control", Mechanical Systems and Signal Processing, Vol. 23, No. 3, 2009, pp. 855-868.

[2]. H. J. Gao, J. Lam,C. H. Wang, "Multi-objective control of vehicle active suspension systems via load-dependent controllers", Journal of Sound and Vibration, Vol. 290, No. 3-5, 2006, pp. 654-675.

[3]. H. P. Du, K. Y. Sze, J. Lam, "Semi-active $\mathrm{H}_{\infty}$ control of vehicle suspension with magneto-rheological dampers", Journal of Sound and Vibration, Vol. 283, No. 3-5, 2005, pp. 981-996.

[4]. M. Zapateiro, N. Luo, H. R. Karimi, et al., "Vibration control of a class of semiactive suspension system using neural network and backstepping techniques", Mechanical Systems and Signal Processing, Vol. 23, No. 6, 2009, pp. 1946-1953.

[5]. R. K. pekgokgoz, M.A. Gurel, "Active suspension of cars using fuzzy logic controller optimized by genetic algorithm", International Journal of Engineering and Applied Sciences (IJEAS), Vol. 2, Issue 4(2010) 27-37.

[6]. Yagiz, N., Hacioglu, Y., "Back stepping control of a vehicle with active suspensions", Control Engineering Practice, 2-11, 2008.

[7]. A. A. Aldair and W. J. Wang, "Design an intelligent controller for full vehicle non linear active suspension systems", International Journal on smart sensing and intelligent systems, Vol.4, No. 2, June 2011.

[8]. Gigih Priyandoko, Musa Mailah, "Fuzzy Logic Active Force Control for an Active Suspension Quarter Car Model”, Journal TeknikMesin, Trisakti, Jun 2005.

[9]. Jiangtao Cao, Honghai Liu, Ping Li, David Brown, "State of Art in vehicle Active suspension Adaptive control systems based on intelligent methodologies", IEEE Interaction on intelligent transportation systems.

[10]. M. Sunwoo, K.C., K.C., and N.J. Huang, "Model reference adaptive control for vehicle active suspension systems", Institute of Electrical and Electronics Engineers Transactions on Industrial Electronics, 38, 217-222, 1991.

[11]. J. Marzbanrad, G. Ahmadi, H. Zohoor, et al., "Stochastic optimal preview control of a vehicle suspension", Journal of Sound and Vibration, Vol. 275, No. 3-5, 2004, pp. 973-990.

[12]. M. Yamashita, K. Fujimori, K. Hayakawa, "Application of H-infinity control to active suspension systems”, Automatica, Vol. 30, No. 11, 1994, pp. 1717-1729.

[13]. S. B. Choi, S. S. Han, "H-infinity control of electrorheological suspension system subjected parameter to uncertainties", Mechatronics, Vol. 14, No. 13, 2003, pp. 639-657.

[14]. H. P. Du, K. Y. Sze, J. Lam, "Semi-active $\mathrm{H}_{\infty}$ control of vehicle suspension with magneto-rheological dampers", Journal of Sound and Vibration, Vol. 283, No. 3-5, 2005, pp. 981-996.

[15]. A. Alleyne, J. K. Hedrick, "Nonlinear adaptive control of active suspensions", IEEE Transactions on Control Systems Technology, Vol. 3, No. 1, 1995, pp. 94-101.

[16]. S. J. Huang, H. Y. Chen, "Adaptive sliding controller with self-tuning fuzzy compensation for vehicle suspension control", Journal of Sound and Vibration, Vol. 16, No. 10, 2006, pp. 607-622.

[17]. T. Yoshimura, "Active suspension of vehicle systems using fuzzy logic", International Journal of Systems Science, Vol. 27, No. 2, 1996, pp. 215-219.

[18]. E. C. Yeh, Y. J. Tsao, "A fuzzy preview control scheme of active suspension for rough road”, IEEE International Journal of Vehicle Design, Vol. 15, No. 1-2, 1994, pp.166-180.

[19]. Gigih Priyandoko, Musa Mailah, "Fuzzy Logic Active Force Control for an Active Suspension Quarter Car Model”, Journal TeknikMesin, Trisakti, Jun 2005.

[20]. S. Yildirim, "Vibration control of suspension systems using a proposed neural network", Journal of Sound and Vibration, Vol. 277, No. 4-5, 2004, pp. 1059-1069. 
[21]. G. Priyandoko, M. Mailah, "Vehicle active suspension system using skyhook adaptive neural active force control", Mechanical Systems and Signal Processing, Vol. 23, No. 3, 2009, pp. 855-868.

[22]. I. Eski, S. Yildirim, "Vibration control of vehicle active suspension system using a new robust neural network control system", Simulation Modelling Practice and Theory, Vol. 17, No. 5, 2009, pp. 778-793.

[23]. Sunwoo, M., Cheok, K.C., Huang, N.J., "Model reference adaptive control for vehicle active suspension systems", Institute of Electrical and Electronics Engineers Transactions on Industrial Electronics, 38, 217-222, 1991.

[24]. Mouleesewaran Senthil Kumar, "Development of active suspension system for automobiles using PID controller", Proceedings of the world congress on engineering 2008, London. U.K.

[25]. Kennedy.J and Russell C. Eberhart, "Swarm Intelligence”, Morgan-Kaufmann, pp 337$342,2001$.

[26]. Eberhart, R. C. and Kennedy. J, "A new optimizer using particle swarm theory", Proceeding of the Sixth International Symposium on Micro Machine and Human Science. Nagoya, Japan, pp. 39-43, 1995.

[27]. Kennedy, J. and Eberhart, R. C, "Particle swarm optimization", Proc. IEEE Int'l conf. on Neural Networks, Piscataway, NJ: IEEE Press, IV pp.1942-1948, 1995.

[28]. Mahfouf, M., Minyou-Chen, D. A. Linkens, "Adaptive Weighted Particle Swarm Optimization (AWPSO) of Mechanical Properties of Alloy Steels", 8th International Conference on Parallel Problem Solving from Nature (PPSN VIII), Birmingham (U.K), 2004. [29]. Xiaohui $\mathrm{Hu}$, Russel Eberhart, Yuhui shi, "Recent advances in particle swarm", Proceeding of the congress on evolutionary computation (CEC-2004), Vol. 1, Piscataway, IEEE Service Center, pp.90-97, 2004.

[30]. Pranay Lahoty and Girish Parmar, "A omparative study of Tuning of PID Controller using Evolutionary Algorithms", International Journal of Emerging Technology and Advanced Engineering, Volume 3, Issue 1, January 2013.

[31]. Mouleesewaran Senthil Kumar, "Development of active suspension system for automobiles using PID controller", Proceedings of the world congress on engineering 2008, London. U.K 